\title{
Human Keratinocyte Cell Lines Differ in the Expression of the Collagenolytic Matrix Metalloproteinases-1, -8, and -13 and of TIMP-1
}

\author{
Beatrice E. Bachmeier ${ }^{1}$, Andreas G. Nerlich ${ }^{2}$, \\ Petra Boukamp ${ }^{3}$, Ralf Lichtinghagen ${ }^{4}$, \\ Harald Tschesche ${ }^{5}$, Hans Fritz ${ }^{1}$ and Edwin Fink ${ }^{1, *}$ \\ ${ }^{1}$ Department of $C$ linical Chemistry and Clinical B iochem- \\ istry, University Hospital of S urgery, Ludwig-Maximilians- \\ University, Nußbaumstr. 20, D-80336 M unich, Germany \\ ${ }^{2}$ Department of Pathology, Ludwig-Maximilians-Univer- \\ sity, Thalkirchner Str. 36, D-80337 Munich, Germany \\ ${ }^{3}$ Division of Carcinogenesis and Differentiation, German \\ Cancer Research Center, Im Neuenheimer Feld 280, \\ D-69120 Heidelberg, Germany \\ ${ }^{4}$ Institute of Clinical Chemistry I, Medizinische \\ Hochschule, Carl-Neuberg-Str. 1, D-30623 Hannover, \\ Germany \\ ${ }^{5}$ Department of B iochemistry, University of Bielefeld, \\ Universitätsstr. 25, D-33615 Bielefeld, Germany \\ ${ }^{*}$ Corresponding author
}

We investigated cells and conditioned media of the three human keratinoc yte cell lines $\mathrm{HaC}$ aT (non-tumorigenic), A5 (benign, tumorigenic) and II-4RT (malignant, tumorigenic) with regard to production and secretion of the collagenases-1 to -3 (MMP-1, MMP-8 and MMP-13) and TIMP-1 using semi-nested RT-PCR, Western blots, ELISA, immunocytochemistry and casein zymography.

Transcripts of MMP-1, $-8,-13$ and TIMP-1 were detected in all cell lines by RT-PCR and the corresponding proteins were found in the cytoplasm of all three cell lines by Western blot analysis and/or immunocytochemistry. The conditioned media of the malignant II-4RT cells contain significantly more MMP-1 and MMP-8 than those of $\mathrm{HaC}$ aT or A5 as evidenced by immunoblotting and ELISA. In addition to the presence of latent MMP-1, zymography also detected the active form of this enzyme. TIMP-1 was found only in extracts of all three cell lines, predominantly in A5.

This study clearly indic ates that the epithelial tumor cells synthesize different collagenases and TIMP-1. The malignant clone secretes increased amounts of distinct collagenases compared to the non-tumorigenic cell line, thereby verifying a correlation between biological behaviour and the amount of collagenases. In addition, we provide clear evidence that MMP-8 is not exclusively found in polymorphonuclear granulocytes, but also in keratinocyte cell lines.
Key words: Collagenase / HaCaT cells / In vitro study / Keratinocyte cell lines / M MP / Tumorigenicity.

\section{Introduction}

The process of tumor invasion requires degradation of the extracellular matrix by proteolytic enzymes (Matrisian 1992; Birkedal-Hansen et al., 1993). Therefore, the balance between production, activation and inhibition of these enzymes is fundamental for the steps involved in the tumor-associated matrix turnover (Schmitt et al., 1992; Mignatti and Rifkin, 1993; J ohnsen et al., 1998). In particular, an increased expression of matrix metalloproteinases (MMPs) has been shown to be involved in tumor invasion and metastasis (Basset et al., 1997; J ohnsen et al., 1998).

Until now more than 17 members of the family of zincdependent MMPs have been identified (Woessner, 1998). Due to their substrate specifity and structure, MMPs can be classified into collagenases, stromelysins, gelatinases, membrane-type MMPs and other MMPs (Kähäri and Saarialho-Kere, 1997). During tumor invasion, collagenases are particulary important as these enzymes are able to degrade the collagenous connective tissue which represents the bulk of the interstitial matrix.

The three mammalian collagenases known, i. e. the fibroblast-type interstitial collagenase, the neutrophil collagenase, and collagenase- 3 differ in their substrate preferences. The fibroblast-type interstitial collagenase (MMP-1, collagenase-1; Goldberg et al., 1986) prefers type III collagen over type I, II, VII and X (Gadher et al., 1989; S eltzer et al., 1989). It is widely expressed in various cell types including fibroblasts, chondrocytes, macrophages, endothelial cells and keratinocytes (Freije et al., 1994). Increased levels of this enzyme have been detected in various carcinomas, e. g. thyroid and gastric cancer (Kameyama, 1996, Sakurai et al., 1997a, b).

The neutrophil collagenase (MMP-8, collagenase-2; Hasty et al., 1987) preferentially cleaves type I and II collagens, but also type III collagen. This enzyme was thought to be synthesized exclusively by polymorphonuclear neutrophils (PMN) where it is stored as a latent proenzyme in the specific granules (Murphy et al., 1977; Mainardi et al., 1991). However, in vivo MMP-8 expression has recently been observed in mononuclear fibroblast-like cells in the rheumatoid synovial membrane, and MMP-8 mRNA was detected in cultured rheumatoid synovial fibroblasts, hu- 
man endothelial cells and human chondrocytes (Chubinskaya et al., 1996; Cole et al., 1996; Hanemaaijer et al., 1997).

The collagenase-3 (MMP-13; Freije et al., 1994) shows an exceptionally wide substrate specifity compared to other M MPs. In addition to fib rillar type I, II and III collagens it also degrades type IV, IX, X and XIV collagen, gelatin, tenascin, fibronectin and proteoglycan coreproteins (Knäuper et al.,1996; Mitchell et al.,1996). Collagenase-3 is expressed by different malignant tumors including breast carcinoma (Freije et al., 1994) and squamous cell carcinoma of the skin, head and neck (Airola et al., 1997; J ohansson et al., 1997a; Cazorla et al., 1998).

Activation of MMPs is controlled by specific inhibitors, termed 'tissue inhibitors of metalloproteinases' (TIMPs). So far 4 TIMPs have been characterized which differ in their inhibitory activities for the various MMPs. Thus, TIMP -1 predominantly inhibits M M P $-1,-3$ and -9 (Mackay et al., 1992), while TIMP-2 preferentially binds to MMP-2 (Goldberg et al., 1989). Besides these inhibitory effects, TIMPs exert other biologically relevant functions and even appear to be involved in the activation of certain MMPs.

So far it is unclear to what extent epithelial tumor cells and the neighbouring stromal cells are responsible for the elevated levels of collagenases in cancer tissues. In order to elucidate the contribution of the tumor cells, we investigated whether the differences in tumorigenicity in a model system of three closely related human keratinocyte cell lines (Boukamp et al., 1988, 1990) are reflected by their profiles of constitutively expressed collagenases.

The cell lines investigated were $\mathrm{HaCaT}$, a spontaneously immortalized human keratinocyte cell line (Boukamp et al., 1988), and the two clones A5 and II-4RT which were derived from $\mathrm{HaCaT}$ by stable transfection with the cellular Ha-ras oncogene (Boukamp et al., 1990). When implanted into athymic mice $\mathrm{HaCaT}$ cells are non-tumorigenic, A5 cells form benign cysts and II-4RT cells develop locally invasive squamous cell carcinomas. Thus the three cell lines represent a unique model of closely related cells with defined in vivo tumorigenicity.
Our approach is based on recent observations that in this model the amounts of gelatinases (MMP-2, -9) and stromelysins (MMP-3, $-7,-10)$ synthesized and secreted increase with tumorigenicity, thus providing a potential link between these enzymes and the cellular behaviour (Bachmeier et al., 1998; 2000).

In the present study we provide evidence that all cell lines express the collagenases MMP-1, -8 and -13 as well as TIMP-1. Thus, MMP-8, the neutrophil collagenase, is not specific for leukocytes, but can also be expressed by epithelial tumorcells. The locally invasive cell line secretes increased amounts of MMP-1 and -8; furthermore, in addition to the latent enzyme also active M M P-1 is present in the media. These observations suggest that the collagenases expressed by epithelial tumor cells may directly contribute to invasive tumor growth. In addition, the presence of several collagenases indicates the redundancy of this proteolytic system.

\section{Results}

\section{Detection of mRNAs of Collagenases and TIMP-1}

Analysis of total RNA by semi-nested RT-PCR demonstrated that the three cell lines express MMP-1 (Figure 1, lanes 1 and 2), MMP-8 (lanes 3 and 4), M MP-13 (lanes 5 and 6) and TIMP-1 (lanes 7 and 8 ). P rimers were chosen so that the PCR amplicons included exon-exon transitions (see Table 1) and thus amplification of genomic DNA would result in products easily recognizable by their size. In addition, the identity of the amplic ons was verified by digestion with restriction endonucleases (Table 1, Figure 1).

\section{Detection of C ollagenases and TIMP-1 in Cells and Cell Extracts}

Protein expression of M MP-1, - $8,-13$ and TIMP-1 was detected in extracts and conditioned media (see section below) of all three cell lines by means of Western blots, immunohistochemistry, ELISA, and zymography; the high

Table 1 Primers Used for PCR Amplification.

\begin{tabular}{lll}
\hline Primer & Sequence & Location \\
\hline MMP-1 forward & 5'-AGATGTGGAGTGCCTGATGT-3' & exon 2 \\
MMP-1 reverse (outer) & 5'-CCTGCAGTTGAACCAGCTAT-3' & exon 9 \\
MMP-1 reverse (inner) & 5'-GTGCGCATGTAGAATCTGTC-3' & exon 7 \\
MMP-8 forward & 5'-ACCAATTACCAAGCAACCAG-3' & exon 2 \\
MMP-8 reverse (outer) & 5'-GGGATACATCAAGGCACCAG-3' & exon 5 \\
MMP-8 reverse (inner) & 5'-GAGCAGCAACAAGAAACAAG-3' & exon 5 \\
MMP-13 forward & 5'-CCAACCCTAAACATCCAAAAAC-3' & exon 6 \\
MMP-13 reverse (outer) & 5'-CACCACAAAATGGAATTGCTG-3' & exon 9 \\
MMP-13 reverse (inner) & 5'-GGCATGACGCGAACAATAC-3' & exon 9 \\
TIMP-1 forward & 5'-CCAGAGAGACACCAGAGAAC-3' & exon 1/2 \\
TIMP-1 reverse (outer) & 5'-GAGGTAAGTGCCATGGTGAG-3' & exon 2 \\
TIMP-1 reverse (inner) & 5'-ACTCACCGAGGTCGGAATTG-3' & exon 2 \\
\hline
\end{tabular}

All primers were designed using the GenBank CDNA sequences for MMP-1 (accession number U78045), M MP-8 (accession number J 05556), M MP-13 (accession number X75308), and TIM P-1 (accession number Y09720). 


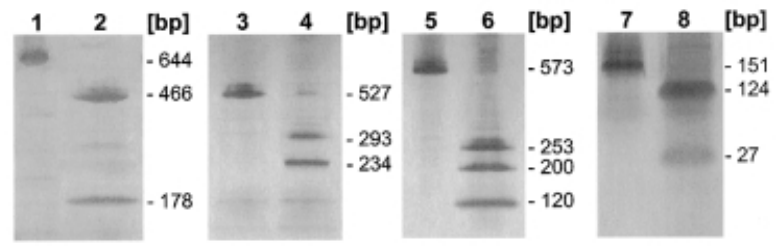

Fig. 1 Detection of MMP-1, -8, -13, and TIMP-1 mRNA by Semi-Nested RT-PCR.

Data are shown for M M P-1 (lanes 1 and 2), M M P-8 (lanes 3 and 4), M M P-13 (lanes 5 and 6) and TIM P-1 (lanes 7 and 8). Reverse transcription and semi-nested PCR were performed with total RNA from about $10^{6}$ cells. Aliquots of the PCR mixtures before (lanes 1 , 3,5 and 7) and after digestion with restriction endonucleases (lanes 2, 4, 6 and 8) were subjected to PAGE. The endonucleases Styl, Fokl, Ddel and Haelll were used to digest amplicons from MMP-1, - 8, -13, and TIMP-1, respectively. The gels shown are the results from $\mathrm{HaCaT}$ cells, representatively for all three cell lines.

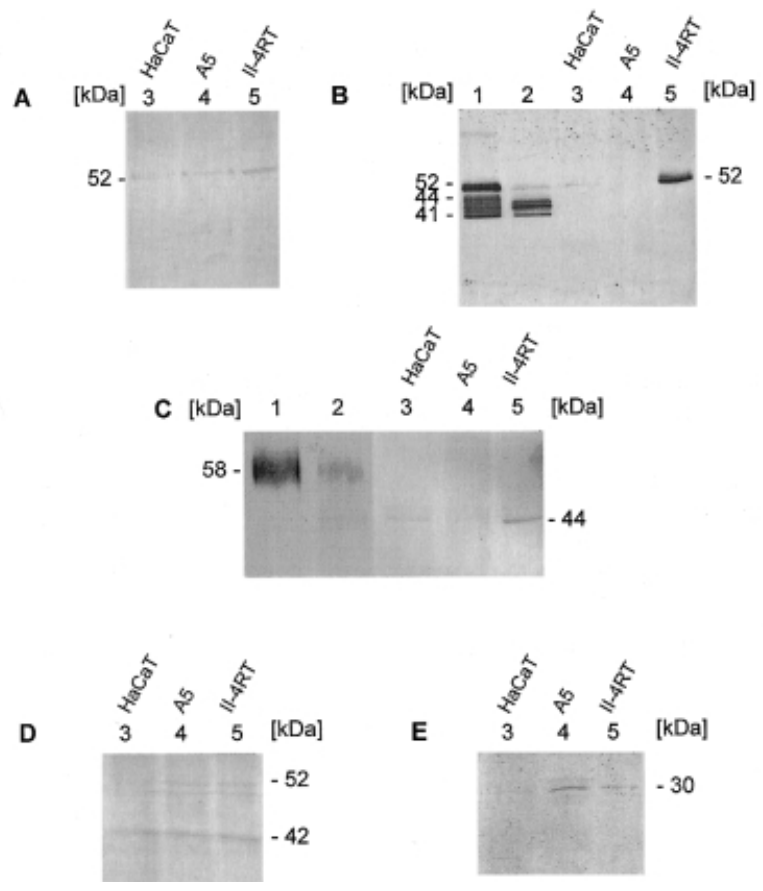

Fig. 2 Western Blot Analyses of Cell Extracts and Serum-Free Conditioned Media of HaCaT, A5 and II-4RT Cells Using Antibodies Specific for MMP-1, -8, -13, and TIMP-1.

Extracts ( $60 \mu \mathrm{g}$ protein) analyzed for MMP-1 (A), MMP-13 (D), and TIMP-1 (E). Conditioned Media ( $15 \mu \mathrm{g}$ protein) analyzed for MMP-1 (B), and MMP-8 (C). HaCaT cells: lanes 3; A5 cells: lanes 4; II-4RT cells: lanes 5; MMP-1 and -8 controls $(B, C)$ : lanes 1 : without APMA; lanes 2: after APMA treatment. sensitivity of zymography and immunohistochemistry allowed to detect distinct proteins where the limits of the Western blot technique were already reached.

Western Blots MMP-1 was detected as faint bands of latent enzyme (52 kDa, Figure $2 \mathrm{~A}$ ) and MMP-13 as bands of latent (52 kDa, Figure 2D) as well as active enzyme (42 kDa, Figure 2D). About equal amounts were found in extracts of all three cell lines. MMP-8 was not detected in the extracts of any cell line by immunoblotting.

In addition, bands of TIMP-1 at $\sim 30 \mathrm{kDa}$ were detectable in extracts of all three cell lines. The intensity of the TIMP-1 band was highest in benign A5 cell extracts (Figure 2E; lane 3), lower in those of malignant II-4RT (Figure $2 \mathrm{E}$; lane 4 ) and hardly detectable in those of $\mathrm{HaCaT}$ (Figure 2E; lane 1) (see also Table 2).
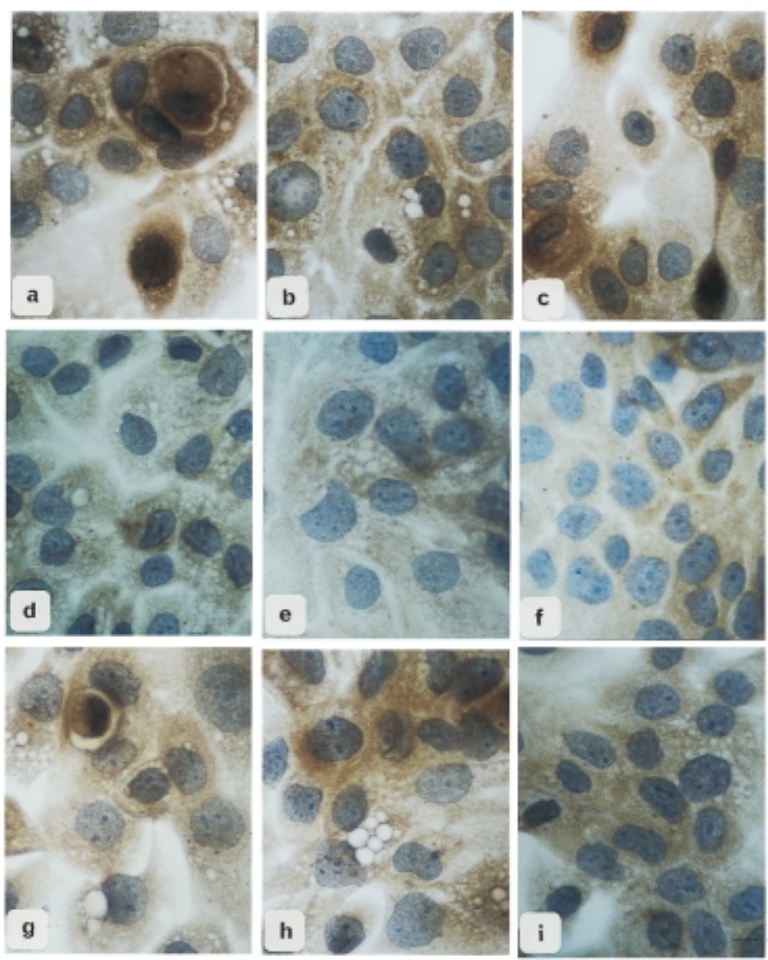

Fig. 3 Immunocytochemical Staining of MMP-1, MMP-8 and MMP-13.

In all three cell lines a cytoplasmic positive staining was seen for MMP-1 [HaCaT, (a); A5, (d); II-4RT, (g)] M MP-8 [HaCaT, (b); A5, (e); II-4RT, (h)] and MMP-13 [HaCaT, (c); A5, (f); II-4RT, (i)]. Magnification $340 \mathrm{x}$.

Table 2 Detection of MMP-1, $-8,-13$ and TIMP-1 in Extracts and Conditioned Media on Western Blots.

\begin{tabular}{lllllllll}
\hline & \multicolumn{3}{c}{ Extracts } & \multicolumn{5}{c}{ Conditioned media } \\
\hline & HaCaT & A5 & II-4RT & Form & HaCaT & A5 & II-4RT & Form \\
\hline MMP-1 & + & + & + & latent & + & - & +++ & latent \\
MMP-8 & - & - & - & - & ++ & $(+)$ & +++ & active \\
MMP-13 & + & + & + & latent & - & - & - & - \\
TIMP-1 & + & + & + & active & & & & \\
\hline
\end{tabular}

The intensities of the bands were scored from +++ (strong signal) to - (no signal). 
Table 3 Scoring of the Immunocytochemical Staining.

\begin{tabular}{lccc}
\hline & HaCaT & A5 & II-4RT \\
\hline MMP-1 & 12 & 12 & 12 \\
MMP-8 & 3 & 6 & 7.5 \\
MMP-13 & 8 & 8 & 8 \\
\hline
\end{tabular}

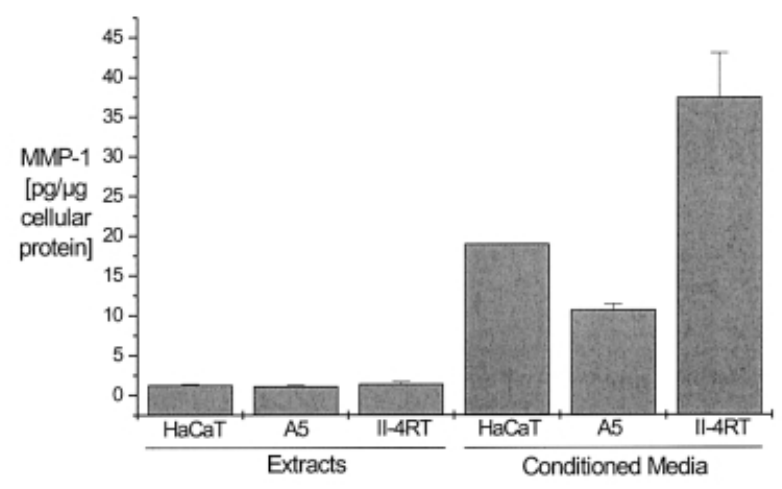

Fig. 4 Quantification of MMP-1 in Extracts and Conditioned Media of $\mathrm{HaCaT}, \mathrm{A} 5$, and II-4RT Cells.

MMP-1 was quantified using the Amersham Biotrak MMP-1 ELISA kit. Values represent mean \pm SD.

Immunocytochemistry The immunocytochemical analysis revealed the presence of immunoreactive MMP-1, -8 and -13 in all three cell lines, although to a different degree. The enzymes were localized intracytoplasmatically in a granular pattern. There was no accentuated membrane staining. Using a scoring system (see also Table 3) for the evaluation of the amounts of protein, we found equally intense stainings for MMP-1 and -13 in $\mathrm{HaCaT}$ (Figure 3a, g), A5 (Figure 3b, h) and II-4RT cells (Figure $3 c$, i). In contrast, the MMP-8 staining score was lower in $\mathrm{HaCaT}$ cells (Figure $3 \mathrm{~d}$ ) compared to the two tumorigenic cell clones - the benign A5 cells (Figure $3 e$ ) and the malignant II-4RT cells (Figure 3f) - which showed only minor differences.

ELISA The amounts of MMP-1 protein in the cytoplasm of the three cell lines were quantified by MMP-1-ELISA. As shown in Figure 4 the amounts of MMP-1 protein in $\mathrm{HaCaT}, \mathrm{A} 5$ and II-4RT were virtually identical (1.3, 1.1, and $1.4 \mathrm{pg} / \mathrm{\mu g}$ of cellular protein, respectively).

\section{Detection of Collagenases and TIMP-1 in Conditioned Media}

Western B lot In contrast to the analysis of cytoplasmic collagenases- 1 and -2 the pattern of secreted MMP- 1 and MMP-8 differed significantly between malignant II-4RT cells and the other two cell lines (Figure $2 B$ and $2 C$ ): while MMP-1 could not be found in media of benign $A 5$ cells (Figure 2B, lane 4), it was present in small amounts in those of normal $\mathrm{HaCaT}$ cells (Figure $2 \mathrm{~B}$, lane 3 ) and enhanced in media of malignant II-4RT cells (lane 5). Secreted M M P-8 was visible as a $44 \mathrm{kDa}$ band of active M MP-8. It was pre- sent in media of $\mathrm{HaCaT}$ (Figure $2 \mathrm{C}$, lane 3 ) and $\mathrm{A} 5$ cells (hardly visible in Figure 2C, lane 4) and severalfold elevated in those of malignant II-4RT cells (Figure 2C, lane 5) (see also Table 2).

To verify whether the MMPs detected by Western blotting represent the latent or the active forms, purified MMP-1 and - 8 with and without APMA treatment were used as controls. The $52 \mathrm{kDa}$ band of the cell culture supernatants comigrated with the $52 \mathrm{kDa}$ band of the control (MMP-1 without APMA treatment; Figure $2 B$, lane 1 ), indicating the presence of latent MMP-1 in the samples. In addition also active MMP-1 (44-41 kDa) was visible in the samples not treated with APMA (Figure 2B, lane 1). The 52 $\mathrm{kDa}$ band almost completely disappeared upon treatment of MMP-1 with APMA, so that only the bands of active MMP-1 (44-41 kDa) were visible (Figure 2B, lane 2). Application of MMP- 8 controls (latent form: Figure $2 \mathrm{C}$, lane 1 ; after APMA activation: Figure 2C, lane 2) demonstrated that the $44 \mathrm{kDa}$ band corresponded to the active form of neutrophil collagenase (see also Table 2).

TIMP-1 and M MP-13 were not detectable in the conditioned media of any of the cell lines.

ELISA The enhanced secretion of MMP-1 by the malignant cells was confirmed and quantified by ELISA. As shown in Figure 4, $\mathrm{HaCaT}$ cell culture supernatants contained $19 \mathrm{pg} / \mu \mathrm{g}$, those of benign A5 $10.7 \mathrm{pg} / \mu \mathrm{g}$ and of malignant II-4RT $36 \mathrm{pg} / \mu \mathrm{g}$ of secreted protein.

Zymography In addition to the latent form of MMP-1 (52 $\mathrm{kDa}$ ) the active enzyme ( $41 \mathrm{kDa}$ ) was found in conditioned media of benign A5 (Figure 5, lane 3) and malignant II-4RT (Figure 5 , lane 4 ) cells by means of zymography. Comparis on of the band pattern with that of M MP-1 controls clearly demonstrated that the lytic zones at 52 and 41 kDa correspond to the latent and active forms of MMP-1 (Figure 5, lane 1). The amount of active interstitial collagenase is very low and obviously below the detection limit of the less sensitive Western blot technique. In addition to the bands corresponding to MMP-1 also lytic bands at 60 and $56 \mathrm{kDa}$ were obtained for all cell lines (Figure 5 ) which were not further characterized in this study.

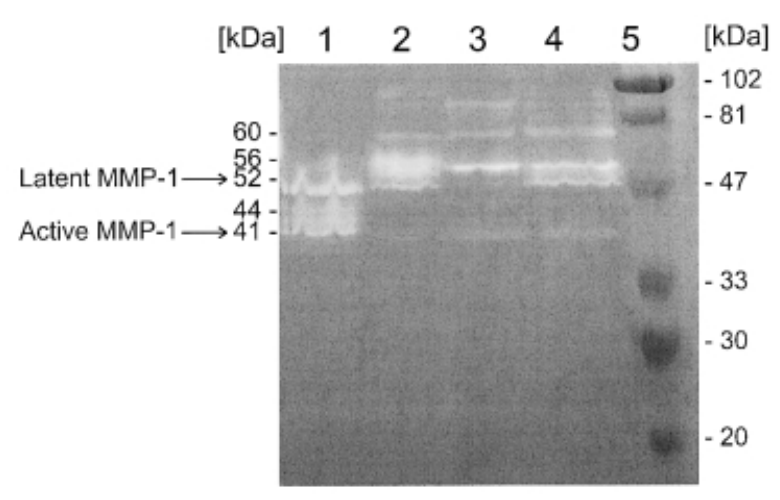

Fig. 5 Casein-Zymography of Conditioned Media.

Lane 1, M MP-1 control; lanes 2 - 4, conditioned media of $\mathrm{HaCaT}$, A5 and II-4RT cells ( $20 \mu \mathrm{g}$ protein per lane); lane 5 , marker proteins. 


\section{Discussion}

The dissolution of the extracellular matrix is a prerequisite for invasive malignant growth. Recent studies provide a large body of evidence that particularly matrix metallop roteinases (MMPs) are involved in this tissue degradation. Based on their structures and substrate specificities the M MPs have been classified into membrane-bound MMPs (MT-MMPs), which are mainly involved in the activation of non-bound MMPs, gelatinases (MMP-2, -9), which degrade non-helical collagen and non-collagenous proteins, stromelysins (M MP-3, -7, -10,-11), which mainly dissolve glycoproteins, and collagenases (MMP-1, -8, -13), which are the only mammalian enzymes that are able to cleave fibrillar collagens.

This substrate diversity is assumed to have major biological implications, particularly during the invasive growth of malignant tumors. Thus, the cleavage of the basement membrane as the first barrier for malignant epithelial cells by gelatinases and stromelysins needs to be followed by the breakdown of other interstitial collagen by collagenases. The production and activation of collagenases therefore is pivotal for further tumor growth and local tumor expansion. Indeed, various studies provide evidence that in vivo an enhanced production of interstitial collagenases is associated with a more aggressive growth potential and poor clinical outcome (Murray et al., 1996, 1998; Cazorla et al., 1998; Airola et al., 1999; McC arthy et al., 1999).

In a previous study (Bachmeier et al., 1998; 2000) we have shown that $\mathrm{HaCaT}$ keratinocytes and the derived clonal cell lines of different tumorigenicity represent an interesting in vitro model for studying the biological role of the expression and secretion of gelatinases and stromelysins: the malignant cell clone (termed II-4RT, derived from the parental cell line $\mathrm{HaCaT}$ by $\mathrm{c}-\mathrm{Ha}$-ras oncogene transfection, Boukamp et al., 1990) produces larger amounts of these enzymes than the benign cell line $A 5$ and particulary the parental non-tumorigenic cell line $\mathrm{HaCaT}$. This protease profile correlates well with the biological behaviour of these cell lines that has been extensively characterized by implantation studies in athymic mice: injection of $\mathrm{HaCaT}$ cells resulted in rapidly regressing nodules, A5 cells formed slowly expanding cysts without signs of invasive growth, while II-4RT cells produced locally invasive squamous cell carcinomas (Boukamp et al., 1990). Thus, the enhanced production and secretion of gelatinases and to some extend of stromelysins in the tumorigenic clones may result in the degradation of type IV collagen and other components of the basement membrane.

In the present report we extended our studies on this model system to the analysis of the collagenases M MP -1, MMP-8 and MMP-13. These three collagenases are of special interest because they are able to degrade fibrillar collagens in the extracellularspace, making them susceptible to further degradation by other MMPs. Thus, secretion of the collagenases enables tumor cells to invade the interstitial matrix.
Using RT-PCR all three cell lines were shown to express the mRNAs of MMP-1, $-8,-13$ and of TIMP -1 , and thus are capable to synthesize the corresponding proteins. On the protein level, MMP-1 was significantly increased in the media of malignant cells when compared to the benign A5 and the non-tumorigenic $\mathrm{HaCaT}$. So far the expression of this enzyme in $\mathrm{HaCaT}$ keratinocytes has not been described; however, several authors have reported the presence of MMP-1 in primary cultures of human squamous cell carcinomas (Petersen et al., 1987; Bailly et al., 1990). Interestingly, in addition to the latent form of M MP- 1 also the active enzyme was found in the media of tumorigenic cell lines as detected by zymography, indicating that this collagenase may be activated by the tumor cells themselves even without the support of stromal cells. The intracellular levels of MMP-1 were about equal in the three cell lines as shown by ELISA, immunocytochemistry and Western blotting. The higher proportion of M MP-1 in media of the malignant II-4RT cells suggests that production and secretion of MMP-1 in II-4RT cells are enhanced in comparison to $\mathrm{A} 5$ and $\mathrm{HaCaT}$ cells and are linked to the malignant infiltrative behaviour.

In addition to MMP-1, MMP- 8 was detected in all cell lines. The occurrence of this enzyme has so far not been reported in epithelial tumor cell lines, but was found in the granules of neutrophil leukocytes (Murphy et al., 1977; Mainardi et al., 1991) and also in other non-epithelial cells such as rheumatoid synovial fibroblasts, endothelial cells (Hanemaaijer et al., 1997) and human chond rocytes (Chubinskaya et al., 1996; Cole et al., 1996). Cell-associated MMP-8 was identified in all three cell lines by immunocytochemistry, but not by Western blotting, most likely due to the lower sensitivity of this technique. MMP-8 was found on immunoblots of conditioned media of $\mathrm{HaCaT}$ and II-4RT; larger amounts are secreted by the malignant II-4RT than by non-tumorigenic HaCaT, while no MMP-8 was seen in media of A5 cells. As M MP-8 is known to hydrolyze native type I collagen with high efficiency (Hanemaaijer et al., 1997), the secretion of this enzyme may be important for the invasive behavior of tumor cells.

MMP-13 was observed exclusively in cellular extracts as evidenced by Western blotting and by immunocytochemistry, but not in conditioned media. This is well in line with the previous report by J ohansson et al. (1997b) who did not find MMP-13 in the media of unstimulated $\mathrm{HaCaT}$ cells; however, they reported that stimulation by TNF- $\alpha$ and TGF- $\beta$ resulted in a release of the enzyme into the media. In vivo studies on various tumors revealed MM P-13 to be expressed by the epithelial tumor cells (V ohansson et al., 1997a; Cazorla etal., 1998; Balbin et al., 1999); in these cases the expression of MMP-13 may be due to stimulation by cytokines released e. $\mathrm{g}$. by stromal cells.

The overall increased secretion of collagenolytic activity by II-4RT as compared to HaCaT and A5 cells seems to be reflected in the in vivo behavior of the cells: while the parental, non-tumorigenic $\mathrm{HaCaT}$ and the benign A5 cells apparently do not destroy their surround ing interstitial matrix in vivo, the malignant II-4RT cells show local dissolu- 
tion of the collagenous matrix (Boukamp et al., 1990) and therefore require collagenolytic activity in order to grow invasively.

Finally, we analyzed the expression of TIMP-1, which is capable to inhibit most MMPs, particularly MMP-1 (Matrisian, 1990). Interestingly, this inhibitor was detected in extracts of all three cell lines but no secretion could be demonstrated. The highest cell-associated levels were found in the tumorigenic, benign A5 cells, intermediate in malignant II-4RT cells, and the lowest in the non-tumorigenic $\mathrm{HaCaT}$ cells. Thus the amounts of cellular TIMP do not correlate well with those of the intracellular or secreted MMPs. At present, the implication of these findings, particularly for the control of the collagenases, is unclear. This subject is further complicated by the observation that TIMPs are not only MMP-inhibitors, but are also involved in protease activation (Strongin et al., 1995).

Taken together, the results presented support the concept that the profile of M M Ps synthesized and secreted by tumor cells correlates with the invasive phenotype of the respective cells. The increased constitutive secretion of MMP-1 and -8 by the malignant II-4RT cells appears to be an important molecular tool for the degradation of the extracellular matrix. Secretion and subsequent activation of M MP-13 seems to require the interaction with stromal cells, since this collagenase is found only in conditioned media of TNF- $\alpha$ / TGF- $\beta$ stimulated but not of unstimulated HaCaT keratinocytes ( ohansson et al., 1997b). Surprisingly, the cell lines not only synthesize the collagenases MMP-1 and MMP-13, which are well known to be tumor-associated, but also the neutrophil collagenase MMP-8. Finally, the results confirm the conclusion of our accompanying study (Bachmeier et. al., 2000) that the system of the three keratinocyte cell lines can serve as a highly valuable model for investigating correlations between the tumorigenic phenotype of cells and the expression of tumor-associated constituents.

\section{Materials and Methods}

\section{Cells and Culture Conditions}

Cell Culture Conditions The keratinocyte cell lines $\mathrm{HaCaT}, \mathrm{A} 5$ and II-4RT (Boukamp et al., 1988, 1990) were cultured at $37^{\circ} \mathrm{C}$ in a humidified atmosphere of $5 \% \mathrm{CO}_{2}$ and $95 \%$ air. The cells were grown in DMEM (1 g/l glucose) supplemented with $10 \%$ heat inactivated fetal calf serum, $0.35 \mathrm{mg} / \mathrm{ml} \mathrm{L}$-glutamine and 0.05 $\mathrm{mg} / \mathrm{ml}$ gentamycin sulfate; for A5 and II-4RT cells gentamycine sulfate was substituted by $0.2 \mathrm{mg} / \mathrm{ml}$ geneticine. The medium was changed every three days. For subcultures cells were harvested after brief treatment with $0.1 \%$ trypsin/EDTA solution and seeded at a dilution of 1:10. Cells between passages 12 and 55 were used for studies.

Preparation of Serum-Free Conditioned Medium Cells were grown to approx. $90 \%$ confluence in $75 \mathrm{~cm}^{2}$ plastic culture flasks containing $15 \mathrm{ml}$ medium. The cultures were rinsed three times with $\mathrm{Ca}^{2+}$ - and $\mathrm{Mg}^{2+}$-free PBS and subsequently $10 \mathrm{ml}$ of serumfree medium was added. After 2 days, the conditioned medium was collected, concentrated by ultrafiltration (exclusion limit 10 $\mathrm{kDa})$, and stored at $-20^{\circ} \mathrm{C}$.
Harvesting of Cells Cells grown to confluence in serum-containing medium were washed three times with $5 \mathrm{ml}$ PBS and harvested by scraping in $5 \mathrm{ml} P B S$. The cell supensions were centrifuged and the cells washed twice by suspension with $50 \mathrm{ml}$ PBS and centrifugation $(10 \mathrm{~min}$ at $300 \mathrm{~g})$. Aliquots of $1.5-1.7 \times 10^{7}$ cells were stored at $-70^{\circ} \mathrm{C}$ until analysis.

Preparation of Cell Extracts $50 \mu$ l lysis buffer $\left(10 \mathrm{mM} \mathrm{Na}_{3} \mathrm{PO}_{4}\right.$; $0.4 \mathrm{M} \mathrm{NaCl} ; 0.2 \%$ Triton X-100) was added to an aliquot of frozen cells. The mixture was sonified and after centrifugation for $14 \mathrm{~min}$ at $15000 \mathrm{~g}$ the supernatant containing the soluble proteins was collected and either analyzed immediately or stored at $-20^{\circ} \mathrm{C}$.

Determination of Protein Concentration Protein concentrations were determined by the BCA protein assay (Pierce, OudBeijerland, Netherlands) with bovine serum albumin as standard.

\section{Zymography}

Electrophoresis was carried out under non-reducing conditions. After renaturation of the proteins by incubation of the gels in $25 \mathrm{~g} / \mathrm{l}$ Triton X-100 at room temperature for $2 \times 10 \mathrm{~min}$ they were incubated in $50 \mathrm{~mm}$ Tris- $\mathrm{HCl}, \mathrm{pH} 7.5$, containing $0.2 \mathrm{M} \mathrm{NaCl}, 0.02 \%$ Brij35 and $10 \mathrm{~mm} \mathrm{CaCl}{ }_{2}$ at $37^{\circ} \mathrm{C}$ for $18 \mathrm{~h}$. The gels were stained with Coomassie Brilliant Blue R-250. After destaining zones of proteolytic activity became visible as transparent bands in the blue gel.

As controls MMP-1 from human rheumatoid synovial fibroblasts (Calbiochem, La J olla, USA) and M MP-8 from human neutrophil granulocytes (Calbiochem) were used. Rabbit muscle phosphorylase $b$, bovine serum albumin, ovalbumin, bovine carbonic anhydrase, soybean trypsin inhibitor, hen egg lysozyme (Bio-Rad prestained markers, low range) were used as molecular mass markers.

\section{Reverse Transcription and Polymerase Chain Reaction}

RNA Extraction Total RNA was extracted from cells according to the method of Chomczynski and Sacchi (Chomczynski and Sacchi, 1987) using TRI Reagent (Sigma, Deisenhofen, Germany). Total RNA was quantified at $260 / 280 \mathrm{~nm}$. Aliquots were stored in DEPC-treated water or $0.1 \mathrm{~m}$ sodium acetate at $-80^{\circ} \mathrm{C}$.

Reverse Transcription cDNAs were synthesized from $1 \mu \mathrm{g}$ of total RNA using the specific outer reverse primers (Table 1). Reactions were carried out with the First Strand cDNA Synthesis Kit (Pharmacia Biotech, Freiburg, Germany) following the manufacturer's instructions.

Semi-Nested PCR The first round of PCR was carried out with $1 / 10$ of the synthesized specific CDNA, 10 pmol of each primer, 40 nmol dNTP, 1 U PANScript polymerase (PAN-Systems), $2.5 \mu \mathrm{l}$ 10x-buffer [16 mM $\left(\mathrm{NH}_{4}\right)_{2} \mathrm{SO}_{4}, 50 \mathrm{~mm}$ Tris/HCl, $0.1 \mathrm{~g} / \mathrm{l}$ Tween-20, $\mathrm{pH} 8.8$ ] in a total volume of $25 \mu \mathrm{l}$. The $\mathrm{MgCl}_{2}$ concentration in the reaction mixture was $6 \mathrm{mM}$ for MMP-1, $2 \mathrm{mM}$ for MMP-8 and - 13 , and $3 \mathrm{mM}$ for TIMP-1.

20 (M M P-1)or 25 (M MP - $8,-13$ and TIM P-1)cycles were carried out with $30 \mathrm{~s}$ denaturation $\left(94^{\circ} \mathrm{C}\right), 30 \mathrm{~s}$ annealing $\left(56^{\circ} \mathrm{C}\right)$, and $30 \mathrm{~s}$ (MMP-8, TIMP-1) or 1 min (MMP-1, MMP- 13 ) synthesis $\left(72{ }^{\circ} \mathrm{C}\right)$.

The second round of PCR with the forward and inner reverse primers was carried out using one $\mu$ l of the first PCR mixture in a total volume of $50 \mu \mathrm{l}$ and 35 PCR cycles. Concentrations of all reagents and cycle profiles were as in the first PCR.

Negative controls were carried out in the same manner but without template.

Characterization of RT-PCR Products PCR products were characterized by restriction fragment analyses and size determination using polyacrylamide gel electrophoresis in $14 \%$ gels containing $10 \%$ glycerol. 


\section{Immunoblotting}

Sixty $\mu$ g protein of cell extract or $15 \mu$ g protein of conditioned media were subjected to SDS-PAGE in $10 \%$ polyacrylamide slab gels under non-reducing conditions. After electrotransfer to a nitrocellulose membrane and blocking with $50 \mathrm{~g} / \mathrm{l}$ low fat dry milk powder in TTBS $(50 \mathrm{~mm}$ Tris-base, $150 \mathrm{~mm} \mathrm{NaCl}, \mathrm{pH} 7.5,1 \mathrm{~g} / \mathrm{l}$ Tween-20) the membranes were incubated for $2 \mathrm{~h}$ in polyclonal rabbit antiserum (for anti-M MP-1 see Lichtinghagen et al., 1995; for anti-TIMP-1 see Geisler et al., 1997; anti-M MP-8 and - 13 were supplied by Dr. Harald Tschesche, Bielefeld), washed three times for $10 \mathrm{~min}$ in TTBS, incubated for $1 \mathrm{~h}$ with a 1:1000 dilution of porcine anti-rabbit immunoglobulin $\mathrm{G}$ alkaline phosphatase conjugate (DAKO) in $10 \mathrm{~g} / \mathrm{l}$ low fat dry milk powder in TTBS. After rinsing twice with TTBS and once with TBS (TTBS without Tween), the membrane was incubated with 5-bromo-4-chloro-3-indolyl phosphate/nitro blue tetrazolium to visualize bands of alkaline phosphatase activity.

Molecular mass marker proteins and purified MMP-1 (150 ng; Calbiochem) and -8 (100 ng; Calbiochem) were used as controls; in some experiments the purified MMPs were activated with APMA prior to electrophoresis.

\section{ELISA}

MMP-1 was quantified in extracts and conditioned media from different passages of the three cell lines using a M M P-1-ELISA Kit (Biotrak, Amersham Buchler, Braunschweig, Germany). The antibody used in this ELISA recognizes the zymogen of MMP-1, the active form and the complex with TIMP-1.

\section{Immunocytochemistry}

For the immunocytochemical localization of MMP-1, - 8 and -13 cells were grown to confluence on silanized sterile glass slides (SuperFrost plus). The medium was discarded, the cells rinsed with Tris buffer, fixed in methanol/acetone (v/v 2:1) for two minutes, and rinsed again. Following incubation with the specific polyclonal primary antibodies (see 'immunoblotting') for 30 minutes $\left(37^{\circ} \mathrm{C}\right)$, rinsing with Tris buffer, and application of the secondary antibody system (Streptavidin-Biotin-Complex method, Hsu and Raine, 1981; DAKO, Hamburg, Germany), the resulting antibody complexes were visualized with diaminobenzidine (Sigma).

Using light microscopy the proportion of positively labeled cells and the staining intensity was quantified. A five step grading score was used for the proportion of stained cells (score $0: 0$ cells stained; score 1: 0 - 25 cells stained; score 2: 26 - 50 cells stained, score 3: 51 - 75 cells stained; score $4:>75$ cells stained) and a four step grading for the staining intensity (score 0 : no positive staining; score 1: faint positive staining; score 2: moderate staining; score 3: strong staining intensity). 10 randomly selected areas (each $0.41 \mathrm{~mm}^{2}$ ) on two different slides of each cell line were evaluated.

This score was calculated by multiplication of the amount of positively labeled cells and the staining intensity.

\section{References}

Airola, K., J ohansson, N., Kariniemi, A.L., Kähäri, V.M., and Saarialho-Kere, U.K. (1997). Human collagenase- 3 is expressed in malignant squamous epithelium of the skin. Invest. Dermatol. 109, 225 - 231.

Airola, K., Karonen, T., Vaalamo, M., Lehti, K., Lohi, J ., Kariniemi, A.L., Keski-Oja, J ., and Saarialho-Kere, U.K. (1999). Expression of collagenases- 1 and -3 and their inhibitors TIMP- 1 and
-3 correlates with the level of invasion in malignant melanomas. Brit. J. Cancer. 80, $733-743$.

Bachmeier, B., Boukamp, P., Lichtinghagen, R., Fusenig, N., and Fink, E. (1998). Comparative study on protease profiles of human keratinocyte cell lines and derived malignant clones. Biol. Chem. 379 (Suppl.), S 47.

Bachmeier, B., Boukamp, P., Lichtinghagen, R., Fusenig, N., and Fink, E. (2000). Matrix M etalloproteinases-2,-3, -7, - 9, and -10, but not MMP-11, are differentially expressed in normal, benign tumorigenic and malignant human keratinocyte cell lines. Biol. Chem. 381, 497- 507.

Bailly, C., Dreze, S., Asselineau, D., Nusgens, B., Lapiere, C.M., and Darmon, M. (1990). Retinoic acid inhibits the production of collagenase by human epidermal keratinocytes. J . Invest. Dermatol. 94, 47- 51.

Balbin, M., Pendas, A.M., Uria, J .A., J imenez, M.G., Freije, J .P., and Lopez-Otin, C. (1999). Expression and regulation of collagenase-3 (MMP-13) in human malignant tumors. APMIS 107, $45-53$.

Basset, P., Okada, A., Chenard, M.P., Kannan, R., Stoll, I., Anglard, P., Bellocq, J .P., and Rio, M.C. (1997). Matrix metalloproteinases as stromal effectors of human carcinoma progression: therapeutic implications. Matrix Biol. 15, 535 - 541.

Birkedal-Hansen, H., Moore, W.G., Bodden, M.K., Windsor, L.J ., Birkedal-Hansen, B., DeC arlo, A., and Engler, J .A. (1993). Matrix metalloproteinases: a review. Crit. Rev. Oral. Biol. Med. 4, $197-250$.

Boukamp, P., Petrussevska, R.T., B reitkreutz, D., Hornung, J ., Markham, A., and Fusenig, N.E. (1988). Normal keratinization in a spontaneously immortalized aneuploid human keratinocyte cell line. J . Cell. Biol. 106, 761 - 771.

Boukamp, P., Stanbridge, E.J., Foo, D.Y., Cerutti, P.A., and Fusenig, N.E. (1990). C-Ha-ras oncogene expression in immortalized human keratinocytes $(\mathrm{HaC}$ aT) alters growth potential in vivo but lacks correlation with malignancy. Cancer Res. 50, $2840-2847$.

Cazorla, M., Hernandez, L., Nadal, A., Balbin, M., Lopez, J .M., Vizoso, F., Fernandez, P.L., Iwata, K., Cardesa, A., Lopez-Otin, C., and Campo, E. (1998). Collagenase- 3 expression is associated with advanced local invasion in human squamous cell carcinomas of the larynx. J. Pathol. 186, 144 - 150.

Chubinskaya, S., Huch, K., Mikecz, K., Cs-Szabo, G., Hasty, K.A., Kuettner, K.E., and Cole, A.A. (1996). Chondrocyte matrix metalloproteinase-8: up-regulation of neutrophil collagenase by interleukin- 1 beta in human cartilage from knee and ankle joints. Lab. Invest. 74, $232-240$.

Cole, A.A., Chubinskaya, S., Schumacher, B., Huch, K., Szabo, G., Yao, J., Mikecz, K., Hasty, K.A., and Kuettner, K.E. (1996). Chondrocyte matrix metalloproteinase-8. Human articular chondrocytes express neutrophil collagenase. J. Biol. Chem. $271,11023-11026$.

Freije, J.M., Diez-Itza, I., Balbin, M., Sanchez, L.M., Blasco, R., Tolivia, J ., and Lopez-Otin, C. (1994). Molecular cloning and expression of collagenase-3, a novel human matrix metalloproteinase produced by breast carcinomas. J. Biol. Chem. 269, 16766 - 16773.

Gadher, S.J ., Schmid, T.M., Heck, L.W., and Woolley, D.E. (1989). Cleavage of collagen type $X$ by human synovial collagenase and neutrophil elastase. Matrix 9, $109-115$.

Geisler, S., Lichtinghagen, R., Boker, K.H., and Veh, R.W. (1997). Differential distribution of five members of the matrix metalloproteinase family and one inhibitor (TIM P-1) in human liver and skin. Cell Tissue Res. 289, 173 - 183.

Goldberg, G.I., Wilhelm, S.M., Kronberger, A., Bauer, E.A., Grant, G.A., and Eisen, A.Z. (1986). Human fibroblast collagenase. Complete primary structure and homology to an oncogene 
transformation-induced rat protein. J . Biol. Chem. 261, 6600 6605.

Goldberg, G.I., Marmer, B.L., Grant, G.A., Eisen, A.Z., Wilhelm, S., and $\mathrm{He}, \mathrm{C} . \mathrm{S}$. (1989). Human 72-kilodalton type IV collagenase forms a complex with a tissue inhibitor of metalloproteases designated TIMP-2. Proc. Natl. Acad. Sci. USA 86, $8207-$ 8211.

Hanemaaijer, R., Sorsa, T., Konttinen, Y.T., Ding, Y., Sutinen, M., Visser, H., van Hinsbergh, V.W., Helaakoski, T., Kainulainen, T., Ronka, H., Tschesche, H., and Salo, T. (1997). Matrix metalloproteinase- 8 is expressed in rheumatoid synovial fibroblasts and endothelial cells. Regulation by tumor necrosis factoralpha and doxycycline. J. Biol. Chem. 272, 31504 - 31509.

Hasty, K.A., J effrey, J J., Hibbs, M.S., and Welgus, H.G. (1987). The collagen substrate specificity of human neutrophil collagenase. J . Biol. Chem. 262, 10048 - 10052.

Hsu, S.M., and Raine, L. (1981). Protein A, avidin, and biotin in immunohistochemistry. Histochem. Cytochem. 29, 1349 - 1353.

J ohansson, N., Airola, K., Grenman, R., Kariniemi, A.L., Saarialho-Kere, U., and Kähäri, V.M. (1997a). Expression of collagenase- 3 (matrix metalloproteinase-13) in squamous cell carcinomas of the head and neck. Am. J. Pathol. 151, 499 - 508.

J ohansson, N., Westermarck, J ., Leppä, S., Häkkinen, L., Koivisto, L., Lopez-Otin, C., Peltonen, J ., Heino, J ., and Kähäri, V.M. (1997b). Collagenase 3 (matrix metalloproteinase 13) gene expression by $\mathrm{HaCaT}$ keratinocytes is enhanced by tumor necrosis factor alpha and transforming growth factor beta. Cell Growth Differ. 8, 243 - 250.

J ohnsen, M., Lund, L.R., Romer, J ., Almholt, K., and Dano, K. (1998). Cancer invasion and tissue remodeling: common themes in proteolytic matrix degradation. Curr. Opin. Cell Biol. $10,667-671$.

Kähäri, V.M., and Saarialho-Kere, U. (1997). Matrix metalloproteinases in skin. Exp. Dermatol. 6, 199 - 213.

Kähäri, V.M., J ohansson, N., Grenman, R., Airola, K., and Saarialho-Kere, U. (1998). Expression of collagenase-3 (M MP-13) by tumor cells in squamous cell carcinomas of the head and neck. Adv. Exp. Med. Biol. 451, 63 - 68.

Kameyama, K. (1996). Expression of M MP-1 in the capsule of thyroid cancer-relationship with invasiveness. Pathol. Res. Pract. $192,20-26$.

Knäuper, V., Lopez-Otin, C., Smith, B., Knight, G., and Murphy, G. (1996). B iochemical characterization of human collagenase- 3. J. Biol. Chem. 271, 1544 - 1550.

Lichtinghagen, R., Helmbrecht, T., Arndt, B., and Boker, K.H. (1995). Expression pattern of matrix metalloproteinases in human liver. Eur. J. Clin. Chem. Clin. Biochem. 33, 65 - 71.

Mackay, A.R., Ballin, M., Pelina, M.D., Farina, A.R., Nason, A.M., Hartzler, J .L., and Thorgeirsson, U.P. (1992). Effect of phorbol ester and cytokines on matrix metalloproteinase and tissue inhibitor of metalloproteinase expression in tumor and normal cell lines. Invasion M etastasis. 12, 168 - 184.

Mainardi, C.L., Pourmotabbed, T.F., and Hasty, K.A. (1991). Inflammatory phagocytes and connective tissue degrading metalloproteinases. Am. J . Med. Sci. 302, 171 - 175.
Matrisian, L.M. (1990). Metalloproteinases and their inhibitors in matrix remodeling. Trends Genet. 6, 121 - 125.

Matrisian, L.M. (1992). The matrix-degrading metalloproteinases. Bioessays 14, $455-463$.

McCarthy, K., Maguire, T., McGreal, G., McDermott, E., O'Higgins, N., and Duffy, M.J . (1999). High levels of tissue inhibitor of metalloproteinase- 1 predict poor outcome in patients with breast cancer. Int. J. Cancer 84, $44-48$.

Mignatti, P., and Rifkin, D.B. (1993). Biology and biochemistry of proteinases in tumor invasion. Physiol. Rev. 73, 161 - 195.

Mitchell, P.G., Magna, H.A., Reeves, L.M., Lopresti-Morrow, L.L., Yocum, S.A., Rosner, P.J ., Geoghegan, K.F., and Hambor, J .E. (1996). Cloning, expression, and type II collagenolytic activity of matrix metalloproteinase- 13 from human osteoarthritic cartilage. J . Clin. Invest. 97, 761 - 768.

Murphy, G., Reynolds, J .J ., Bretz, U., and Baggiolini, M. (1977). Collagenase is a component of the specific granules of human neutrophil leucocytes. Biochem. J . 162, 195 - 197.

Murray, G.I., Duncan, M.E., O'Neil, P., McKay, J .A., Melvin, W.T., and Fothergill, J .E. (1998). Matrix metalloproteinase- 1 is associated with poor prognosis in oesophageal cancer. J. Pathol. 185, $256-261$.

Murray, G.I., Duncan, M.E., O'Neil, P., Melvin, W.T., and Fothergill, J .E. (1996). Matrix metalloproteinase- 1 is associated with poor prognosis in colorectal cancer. Nature Med. 2, 461 - 462.

Petersen, M.J., Woodley, D.T., Stricklin, G.P., and O'Keefe, E.J . (1987). Production of procollagenase by cultured human keratinocytes. J . Biol. Chem. 262, $835-840$.

Sakurai, Y., Otani, Y., Kameyama, K., Hosoda, Y., Okazaki, I., Kubota, T., Kumai, K., and Kitajima, M. (1997a). Expression of interstitial collagenase (matrix metalloproteinase-1) in gastric cancers. J pn. J . Cancer Res. 88, 401 - 406.

Sakurai, Y., Otani, Y., Kameyama, K., Igarashi, N., Kubota, T., Kumai, K., and Kitajima, M. (1997b). The role of stromal cells in the expression of interstitial collagenase (matrix metalloproteinase-1) in the invasion of gastric cancer. J. Surg. Oncol. 66 , $168-172$.

Schmitt, M., Jänicke, F., Moniwa, N., Chucholowski, N., Pache, L., and Graeff, H. (1992). Tumor-associated urokinase-type plasminogen activator: biological and clinical significance. Biol. Chem. Hoppe-Seyler 373, 611 - 622.

Seltzer, J .L., Eisen, A.Z., Bauer, E.A., Morris, N.P., Glanville, R.W., and Burgeson, R.E. (1989). Cleavage of type VII collagen by interstitial collagenase and type IV collagenase (gelatinase) derived from human skin. J. Biol. Chem. 264, 3822 - 3826.

Strongin, A.Y., Collier, I., Bannikov, G., Marmer, B.L., Grant, G.A., and Goldberg, G.I. (1995). Mechanism of cell surface activation of 72-kDa type IV collagenase. Isolation of the activated form of the membrane metalloprotease. J. Biol. Chem. 270, 5331 5338.

Woessner, J .F. (1998). The matrix metalloproteinase family. In: Matrix Metalloproteinases, W.C. Parks and R.P. Mecham, eds. (San Diego, USA: Academic Press), pp. 1 - 14.

Received February 4, 2000; accepted March 24, 2000 